\title{
Patterns of recolonisation and the importance of pit-digging by the crab Cancer pagurus in a subtidal sand habitat
}

\author{
S. J. Hall ${ }^{1}$, D. J. Basford ${ }^{1}$, M. R. Robertson ${ }^{1}$, D. G. Raffaelli ${ }^{2}$, I. Tuck ${ }^{1, *}$ \\ ${ }^{1}$ SOAFD Marine Laboratory, PO Box 101, Victoria Road, Aberdeen AB9 8DB, Scotland \\ ${ }^{2}$ Culterty Field Station, University of Aberdeen, Newburgh, Ellon, Aberdeenshire, Scotland
}

\begin{abstract}
The nature and level of disturbance to a benthic community caused by the pit-digging activities of the crab Cancer pagurus were examined in a shallow sub-tidal sand habitat on the west coast of Scotland. From observations by acoustic tracking we estimate that each individual digs between 6 and 7 pits $\mathrm{d}^{-1}$, with a total of 20 pits dug in a $1000 \mathrm{~m}^{2}$ area each day. Recolonisation of simulated crab pits suggest that the community returned to its original state within 25 to $30 \mathrm{~d}$. This was achieved initially by erosion from the surrounding sediments, followed by the random arrival of adult colonists from the available benthic pool. Feeding or other competitive interactions within disturbed patches were not altered sufficiently to be reflected as changes in the relative abundance of taxa. We estimate that $3.6 \%$ of the habitat will be at some stage of recovery from disturbance by pit-digging at this time of year.
\end{abstract}

\section{INTRODUCTION}

Physical disturbance has been identified as a potentially important force for structuring biological communities. In the case of soft-sediment benthic habitats, such disturbances range from storms operating over kilometres to localised disturbances on a scale of metres or centimetres. On these smaller scales the agents of disturbance are often predators which disrupt the sediment when foraging (e.g. Thistle 1981, Van Blaricom 1982, Oliver \& Slattery 1985, Thrush 1986). Such disturbances can contribute to small-scale spatial variability in infaunal communities by opening patches for invasion and occupancy. In common with many plant communities and marine systems such as coral reefs, soft sediment communities are often considered as spatial mosaics of patches at different stages in a successional sequence (Johnson 1970, 1973, Grassle \& Sanders 1973, Connell 1978).

The edible crab Cancer pagurus (Linnaeus) is a conspicuous member of the subtidal community around the coasts of northern Europe and forms the basis for a

\footnotetext{
- Present address: UMBS, Millport, Isle of Cumbrae, KA28 OEG, Scotland
}

valuable commercial fishery. In soft sediment habitats the principle prey for C. pagurus appears to be large bivalve species (Shelton et al. 1979). To obtain bivalve prey C. pagurus excavate pits in the sediment which are often conspicuous features of the sea bed topography.

In this paper we describe and examine the recolonisation of sediment pits which mimicked those of Cancer pagurus in a shallow sub-tidal sand habitat. In the first part of the paper we describe the physical features of natural pits and use a variety of methods to estimate the level of disturbance caused by $C$. pagurus. We then describe the macrobenthic community dynamics within patches created by the disturbance and compare and contrast our results with those obtained for other habitats. We examine whether food accumulation or release from competition can account for the observed responses of infaunal species to disturbance by pit-digging and assess whether the scales and dynamics of patches are likely to have an important influence on community organisation considered on a large scale.

The contribution of pit-digging by Cancer pagurus to spatial heterogeneity, and the patterns of recolonisation of disturbed patches have previously been examined by Thrush (1986) for a subtidal gravelly 
habitat. Here, we extend these observations to a contrasting habitat and use a more powerful experimental design to examine recolonisation processes. We also measure the dimensions and infilling rates of pits and estimate the rate of pit creation from laboratory data on feeding frequency and from crab movement data obtained by acoustic tracking.

\section{MATERIALS AND METHODS}

Field investigations during this study were conducted in July and August 1989 at Loch Gairloch, Rossshire, Scotland, in a shallow $(15 \mathrm{~m})$ sandy habitat previously described by Hall et al. (1990a, b). The study site is on a shallow sandy bottom $15 \mathrm{~m}$ deep and ca $75 \mathrm{~m}$ from a steeply sloping, moderately sheltered rocky shore. A narrow belt of kelp, Laminaria digitata (Hudson) extends ca $3 \mathrm{~m}$ out from the shore at low water and is associated with large boulder formations which lead directly onto the flat sandy bottom. The sediments are poorly sorted medium sands (median diameter 0.23 to $0.31 \mathrm{~mm}$ ) with only a small fraction (>1\%) less than 63 $\mu \mathrm{m}$. Apart from crab pits and detached macroalgae there are few notable features, such as burrows and mounds. The maximum current speed recorded during continuous measurement over the study period was $0.14 \mathrm{~m} \mathrm{~s}^{-2}$.

Estimating disturbance.

Conventional crab tagging and pit census: A total of 21 dives over a survey period of $35 \mathrm{~d}$ were made between July and August to estimate the level of disturbance caused by Cancer pagurus. All dives were conducted during the day within a $100 \times 50 \mathrm{~m}$ area marked out on the sea floor. On each dive the area was searched for crabs for ca $45 \mathrm{~min}$. When a crab was encountered its behaviour was recorded and, if it was in a pit, it was carefully removed to allow the dimensions of the pit to be measured. The depth, length and width of each pit were recorded. Because pits were almost always oval in area and conical in section, these dimensions provide a reasonable description of pit shape. All newly found crabs were measured, sexed and marked with a standard numbered tag attached to one claw. The identity of any crabs which had been tagged previously was noted. Individuals were returned to their pits where, in the majority of cases $(87 \%)$, they remained. Any crab which left its pit immediately after tagging was noted.

All pits containing crabs were marked using a numbered $75 \mathrm{~cm}$ diameter plastic coated metal ring $(6 \mathrm{~mm}$ cross-sectional diameter) placed around the pit. Infilling was assessed by measuring the dimensions of tagged pits on subsequent surveys. We believe the ring was sufficiently thin so as not to affect rates of infilling, although we did not formally test this assumption.

Acoustic tracking of crab movements: To provide an estimate of disturbance frequency the movements of individual crabs were examined by fixed array acoustic tracking. Movements were followed using an upgraded version of the system described by Hawkins et al. (1980). A full specification for the up-graded system is available on request. The tracking area was bounded by 5 hydrophones $100 \mathrm{~m}$ apart and laid out in a pentagonal arrangement. The area inside the array covered ca 2.2 ha and the position of individuals was recorded every $2 \mathrm{~s}$. Crabs were tagged using conventional $12 \times 40 \mathrm{~mm}$ acoustic pingers (ca $75 \mathrm{kHz}$ pulses of 1.5 ms duration) attached to a claw. In all other respects crabs were treated in an identical manner to those tagged conventionally and the attached pinger was unlikely to affect pit-digging performance.

Sediments and invertebrates in pits. To investigate the dynamics of pit recolonisation an experiment was conducted in which the effects of simulated crab pits were followed over time. The experiment was conducted at $16 \mathrm{~m}$ depth in a $100 \times 2 \mathrm{~m}$ strip of sea bed running parallel to the shore.

To protect the experimental area from uncontrolled disturbances by crabs it was surrounded by a $5 \times 5 \mathrm{~cm}$ mesh wire barrier. The barrier was $30 \mathrm{~cm}$ high and had prongs on the bottom which projected $5 \mathrm{~cm}$ into the sediment and prevented crabs from burrowing underneath. A solid metal shelf projecting horizontally outward from the top of the barrier prevented crabs from climbing into the area. No crabs were ever found inside the barrier. Within the area the positions for 40 simulated crab pits were marked using $75 \mathrm{~cm}$ diameter plastic covered metal hoops. At the start of the experi-
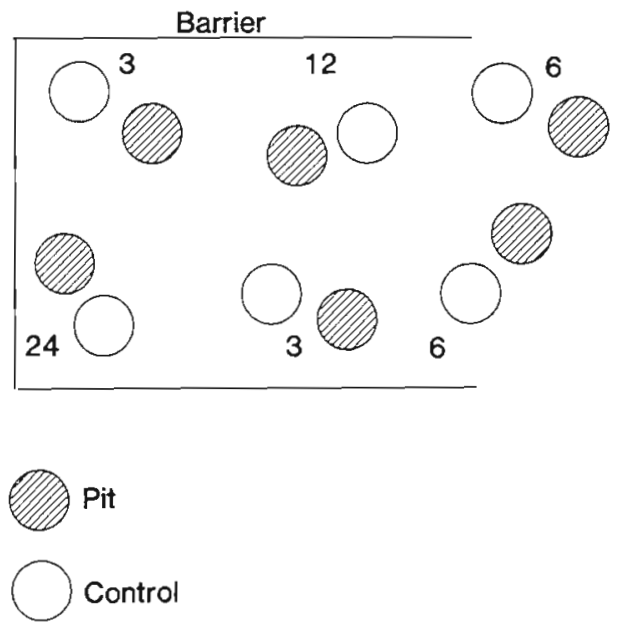

Fig. 1. Spatial layout of simulated crab pit and control areas within a protective barrier 
ment divers dug $50 \mathrm{~cm}$ diameter $\times 5 \mathrm{~cm}$ deep pits within the hoops (Fig. 1) by pushing the sediment away from the centre of the pit using 2 metal trowels. This action mimicked the way crabs excavate pits by pushing sediment out with the back of their claws

At $3,6,12$ and $24 \mathrm{~d}$ after the experiment had begun 10 replicate pits were sampled. The location of the pits to be sampled in any time period was pre-determined using a randomisation procedure. Ten unmanipulated areas, one immediately adjacent to each pit and 30 to $40 \mathrm{~cm}$ from the pit edge, were sampled at the same time. To sample the fauna a $10 \mathrm{~cm}$ diameter corer was placed in the centre of each pit and a $2 \mathrm{~cm}$ diameter core was placed within this to obtain a meiofaunal sample and material for sediment analysis. After removal of the meiofauna core sample the larger macrofaunal core was removed. An identical procedure was adopted for all control replicates.

All samples were fixed in $5 \%$ formalin and macrofauna samples were washed over a $0.5 \mathrm{~mm}$ sieve. Animals retained on the sieve were counted and extracted and identified to species where possible. Meiofaunal cores were separated into the surface section $(0$ to $2 \mathrm{~cm}$ ) and the remainder $(2$ to $10 \mathrm{~cm})$ and were extracted by elutriation (Uhlig et al. 1973). Meiofauna data for the $12 \mathrm{~d}$ sample were not analysed. Sediment analysis was performed by dry sieving (Holme \& McIntyre 1984). Separate analyses were performed for the 2 depth layers. Only samples from 3 and $24 \mathrm{~d}$ were analysed. All samples contained less than $1 \%$ silt.

Owing to oversight samples for analysis of organic material were not taken. In order to test whether organic matter accumulates in crab pits at our study site, 14 natural pits were therefore sampled at a later date along with adjacent undisturbed sediments. Samples were taken with a $2 \mathrm{~cm}$ diameter corer and the organic carbon content of a $0.5 \mathrm{~g}$ subsample of the sediment from the upper $2 \mathrm{~cm}$ was measured by wet oxidation (Strickland \& Parsons 1972, adapted by Basford \& Eleftheriou 1988).

Statistical analysis. For both meiofauna and macrofauna, the effects of simulated crab disturbances on the total numbers of individuals and total numbers of taxa were analysed for each time period using paired $t$-tests. All abundance data were log-transformed $(\log x+1)$ before analysis. For the 16 most abundant macrofaunal taxa difference plots were used rather than making large numbers of paired comparisons. With these plots the difference in taxa abundance between paired pit and control replicates was plotted against the time from the start of the experiment. Where appropriate, leastsquares linear regressions were calculated to describe these data.

If benthic assemblages respond to small but consistent and directional changes in the relative abundance of many prey taxa, this might not be detected by between-treatment comparisons of individual species. Such effects may, however, become apparent using a non-parametric method such as the Sign test (Siegle 1956). We therefore used this test to examine whether there were any consistent effects on taxa abundances.

Two measures of taxa diversity were calculated from the macrofaunal samples after Krebs (1989). Simpson's reciprocal, $D$, was chosen as a Type II index which is most sensitive to changes in more abundant taxa (Peet 1974). The second index is the exponential of the Shannon-Weiner function (exp $H^{\prime}$ ) which is a Type I index, most sensitive to changes in rare taxa. Sample variances for the 2 measures were calculated using the jackknife method.

\section{RESULTS}

\section{Estimates of disturbance}

\section{Conventional tagging}

Ninety-eight crabs were conventionally tagged during the survey period, of which 93 were female. Carapace width ranged from 100 to $200 \mathrm{~mm}$. On the basis of $100 \mathrm{~m}$ transect line swims, we estimated the density of crabs at the time of the study to be between 1 and 2 crabs per $300 \mathrm{~m}^{2}$. At this density we would expect to encounter between 16 and 20 crabs during a survey if the entire $5000 \mathrm{~m}^{2}$ survey area could be covered. However, the requirement to tag crabs and mark and measure pits meant that time was never sufficient to search the whole area adequately and the maximum number of crabs found during a 50 min dive was 12 . To ensure that the whole area was covered adequately, each dive was started in a different place within the area.

Despite tagging a large number of individuals only 10 tagged crabs were found on subsequent dives, indicating that individuals were highly mobile. This conclusion is supported by the results of our acoustic tracking study (see below). Fig. 2a shows the size distribution of tagged crabs.

Over $95 \%$ of all crabs found in the survey area were in pits. Observation by divers suggested that there were 2 types of pit present; small shallow pits which closely matched the boundary of the carapace and in which crabs were largely inactive (hereafter termed resting pits) and larger excavations in which crabs were often found actively digging or feeding on an Ensis sp. Larger crabs tended to be found in larger pits (Fig. 2b), but these data also suggest that all but the smallest crabs dig both large and small pits, but few of intermediate size. This suggestion is supported by the 

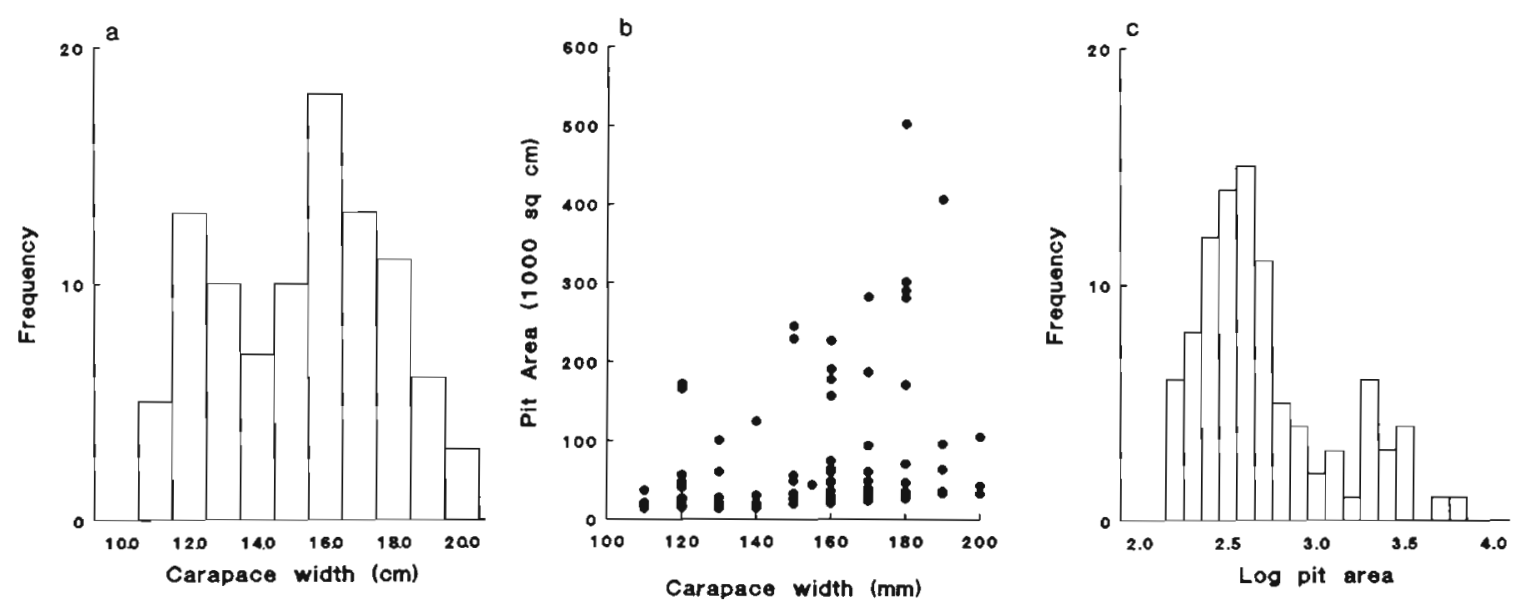

Fig. 2. Cancer pagurus. (a) Crab size distribution. (b) Relationship between pit area and crab size. (c) Frequency distribution of pit areas

observation that the frequency distribution of residuals about a least-squares linear regression through these data is strongly bimodal. Fig. 2c, which shows the frequency distribution of pit areas, confirms our subjective impression that there are 2 kinds of pit and suggests that ca $20 \%$ of pits created are large enough to be associated with feeding.

Ninety-one pits were tagged but, because these were only re-measured when they were encountered at random during searches, the distribution of observations between pits and through time was not uniform. Nevertheless, it is clear that the rate of infilling was very variable between pits (Table 1). For example, one $5 \mathrm{~cm}$ deep pit took only $5 \mathrm{~d}$ to become unrecognisable from surface appearance while another pit of the same depth was still $3 \mathrm{~cm}$ deep after $20 \mathrm{~d}$.

Crab movements and the rate of pit creation

Eight crabs were successfully tagged acoustically during the study and they were followed without interruption for between 1 and 11 d. Fig. 3 shows an example plot of a crab's movements where the proportion of the total number of position fixes is plotted on the vertical axis against crab position on the sea bed given as $x$ and $y$ coordinates. This gives a measure of residence time at each position in the track and clearly shows positions where crabs were stationary. During our survey dives $98 \%$ of stationary crabs were in either feeding or resting pits. To provide an estimate of pit formation rate we have divided the number of stationary periods identifiable from an uninterrupted track by the track duration. These estimates are not independent because up to 3 values were obtained from the same individual, but as a simple description of the data the arithmetic mean of $6.5 \pm 1.7$ SEM pits per day is reasonable. On the basis of both laboratory data on meal size and feeding frequency (Hall \& Tuck unpubl.) and on the proportion of larger sized pits in the wild we expect at least one of these to be a feeding pit.

The mean number of crabs found on a survey dive

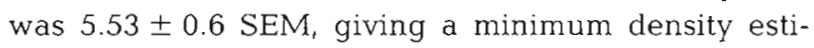
mate of approximately $1 \mathrm{crab}$ per $1000 \mathrm{~m}^{2}$. This estimate is very conservative, however, because we were unable to survey the entire $100 \times 50 \mathrm{~m}$ quadrat on each dive. Also, as increasing numbers of pits were marked in the area more time was spent measuring these than searching for new crabs. The maximum number recorded during a dive was 12 crabs $\left(1 \mathrm{crab}\right.$ per $\left.416 \mathrm{~m}^{2}\right)$ which occurred on the third day of the survey. This latter estimate is closer to the estimates made the previous year during transect surveys which recorded densities of approximately $1 \mathrm{crab}$ per $300 \mathrm{~m}^{2}$. Using a density estimate of approximately 3 crabs per $1000 \mathrm{~m}^{2}$

Table 1. Life of pits as recognisable physical features

\begin{tabular}{|cccc|}
$\begin{array}{l}\text { Depth } \\
(\mathrm{cm})\end{array}$ & $\begin{array}{c}\text { No. of } \\
\text { pits }\end{array}$ & $\begin{array}{c}\text { Minimum life } \\
\text { (d) }\end{array}$ & $\begin{array}{c}\text { Maximum life } \\
\text { (d) }\end{array}$ \\
\hline 3 & 9 & 2 & 16 \\
4 & 7 & 1 & 15 \\
5 & 12 & 5 & $20^{\circ}$ \\
6 & 13 & 5 & $20^{\circ}$ \\
7 & 5 & 2 & $20^{\circ}$ \\
8 & 7 & - & $13^{\circ}$ \\
9 & 4 & - & $22^{\circ}$ \\
10 & 3 & 3 & $10^{\circ}$ \\
12 & 2 & - & $18^{\circ}$ \\
13 & 3 & 12 & $14^{\circ}$ \\
15 & 1 & - & \\
Pits still present after last observations & \\
\hline
\end{tabular}




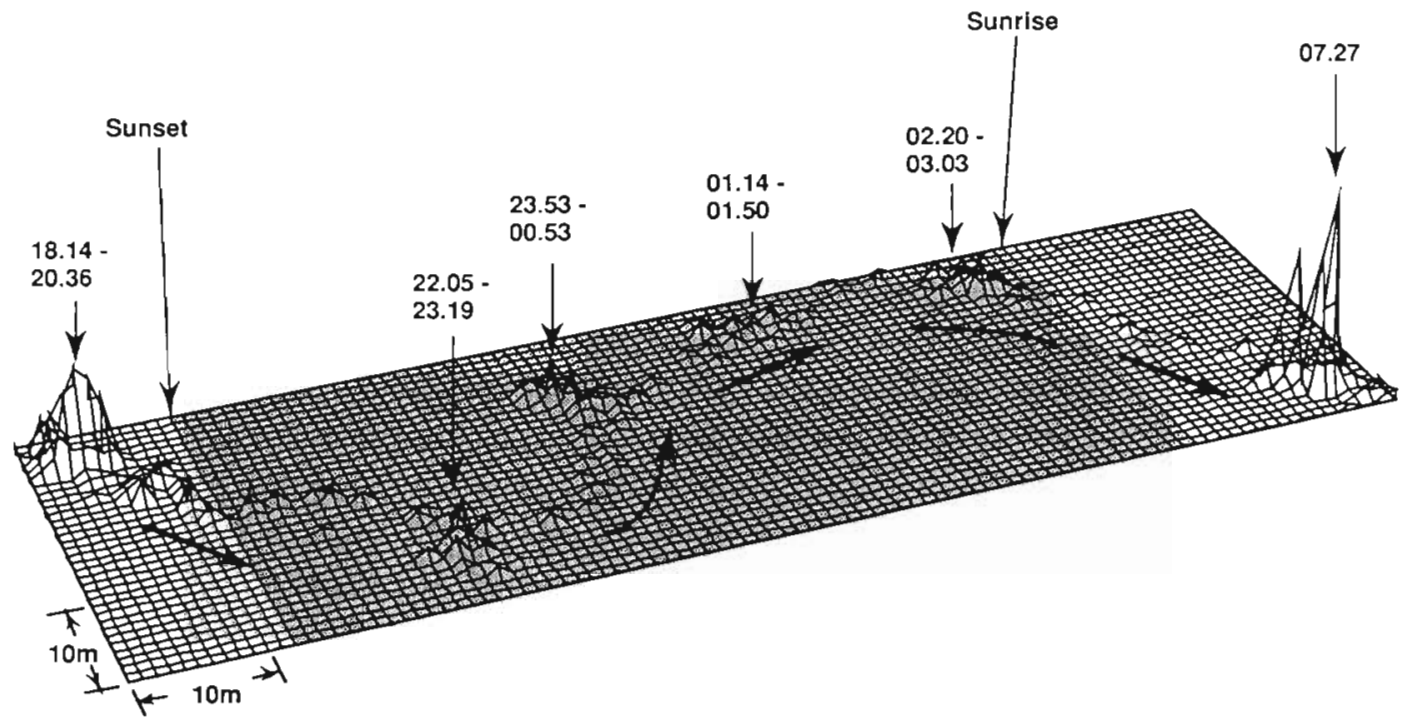

Fig. 3. Cancer pagurus. Example plot of crab movements. (For explanation see text)

and between 6 and 7 pits dug per individual per day, we would expect ca 20 pits to be generated per $1000 \mathrm{~m}^{2}$ each day.

\section{Biological and sediment characteristics of pits}

Effects on sediment characteristics

Table 2 summarises the data for median particle size for 0 to 2 and 2 to $10 \mathrm{~cm}$ depth strata and organic carbon content for the upper $2 \mathrm{~cm}$ of natural crab pits. These data show that pit formation resulted in a statistically significant increase in median particle size. This was mainly due to a small increase in the amount of coarse ( 1 to $4 \mathrm{~mm}$ diameter) material in samples from pits, rather than a reduction in fines. This effect on sediment granulometry persisted up to the end of the experiment in the surface layer, but did not occur at

Table 2. Median particle size data for simulated crab pits and undisturbed control areas. Organic carbon content data for natural crab pits and undisturbed areas. (All data are arithmetic means \pm 1 standard егror)

\begin{tabular}{|c|c|c|}
\hline & Pit & Control \\
\hline \multicolumn{3}{|c|}{ Median particle diameter $(\mathrm{mm}) 0-2 \mathrm{~cm}$ sediment layer } \\
\hline $3 \mathrm{~d}(\mathrm{p}<0.05)$ & $0.36+0.01$ & $0.31+0.01$ \\
\hline $24 \mathrm{~d}(\mathrm{p}<0.01)$ & $0.38+0.01$ & $0.31+0.01$ \\
\hline \multicolumn{3}{|c|}{ Median particle diameter $(\mathrm{mm}) 2-10 \mathrm{~cm}$ sediment laye } \\
\hline $3 \mathrm{~d}$ & $0.28+0.005$ & $0.29+0.007$ \\
\hline $24 \mathrm{~d}$ & $0.29+0.010$ & $0.30+0.010$ \\
\hline \multicolumn{3}{|c|}{ Organic carbon content ( $\mu \mathrm{g} \mathrm{g}^{-1}$ sediment) } \\
\hline & $2.703+0.258$ & $2.432+0.350$ \\
\hline
\end{tabular}

depth. In contrast there was no statistically significant difference in organic carbon content between crab pits and undisturbed areas, indicating that pits are not sites for organic matter accumulation in this habitat.

\section{Effects on the meiofaunal community}

Fig, 4 a \& b shows the total number of individuals and taxa for simulated pits and controls 3,6 and $24 \mathrm{~d}$ after pit creation for the 2 depth strata analysed. The mean numbers of individuals (all taxa combined) were consistently lower for pits at both depth strata, but differences were only significant for the $6 \mathrm{~d}$ sample in the upper layer. The number of taxa (Fig. 4c \& d) showed no consistent pattern at either depth. For the upper sediment layer all taxa had lower mean abundance after 3 and $6 \mathrm{~d}$ and even after $24 \mathrm{~d}$ the only taxon for which mean abundance in pits exceeded controls was harpactacoid copepods. Despite the consistent pattern of lower mean abundance in pits, this was only significant for nematodes sampled on Day 3. A similar pattern of lower mean abundance in simulated pits occurred in the deeper sediment layer; out of 15 comparisons, only one (harpactacoid copepods after $3 \mathrm{~d}$ ) showed lower values in controls. Once again, however, only 2 comparisons on Day 3 showed significant differences (gastrotrichs and ciliates).

\section{Effects on the macrofaunal community}

Fig. 5 summarises the data on numbers of individuals and taxa for the macrofaunal community and shows a statistically significant reduction between simulated 

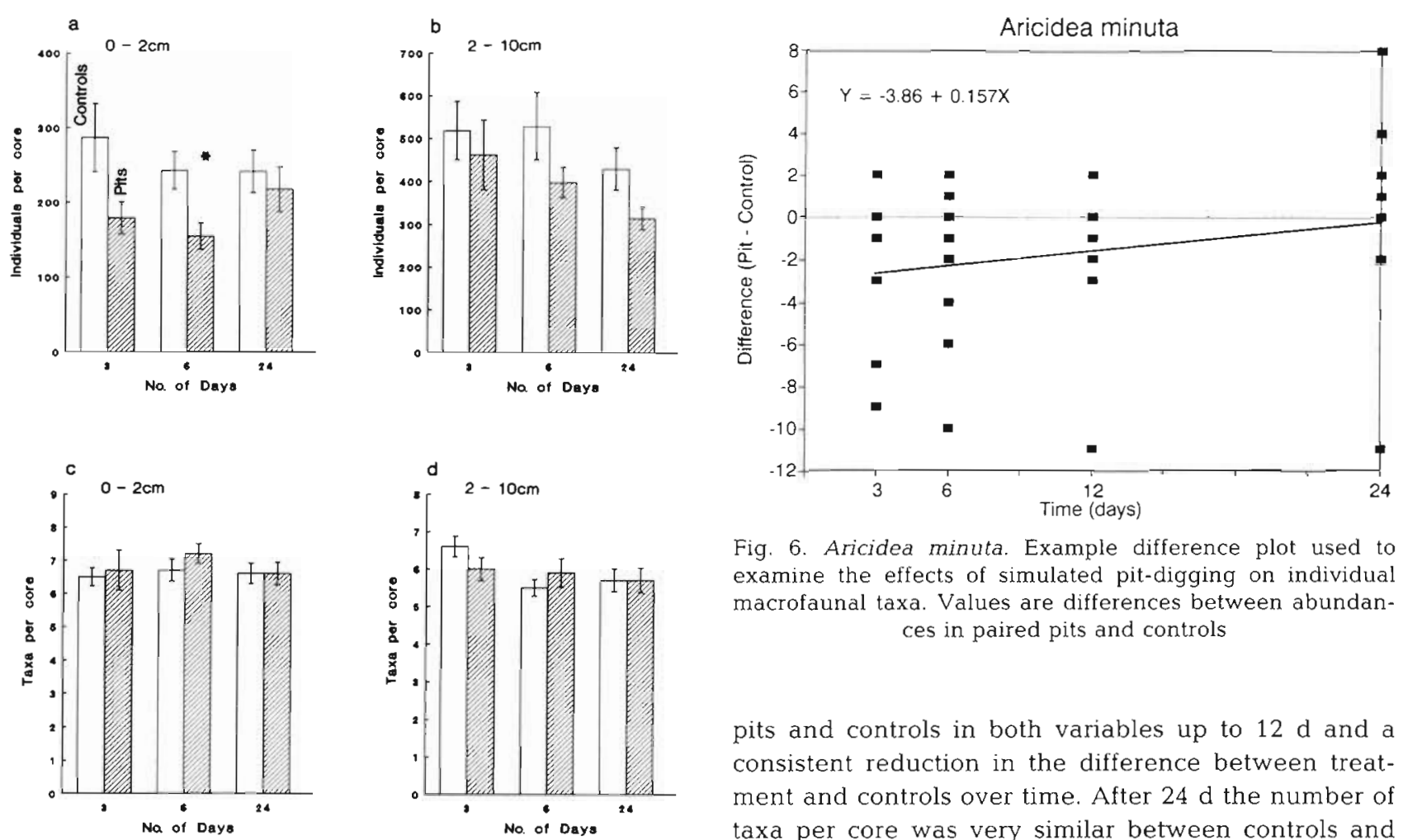

Fig. 4. Effects of simulated pit-digging on the total number of meiofauna individuals and taxa. Hatched bars: pits; open bars: controls; asterisk denotes significant different between pits and controls, $=p<0.05$. Data are arithmetic means + 1 SEM
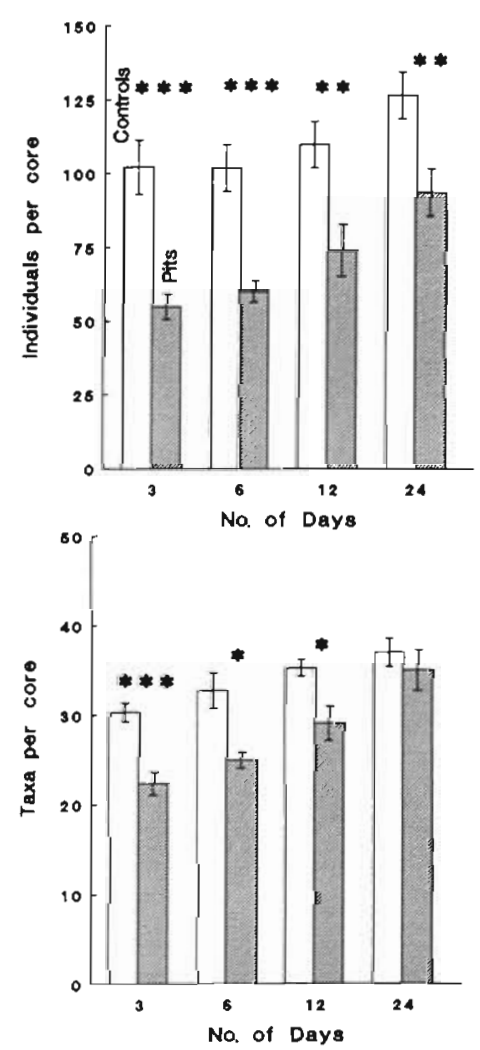

Fig. 5. Effects of simulated pit-digging on the total number of macrofauna individuals and taxa. Hatched bars: pits; open bars: controls, asterisk denotes significant different between pits and controls $\cdot p<0.05, \quad \cdots p<0.01$, $\cdots p<0.001$. Data are arithmetic means +1 SEM

Fig. 6. Aricidea minuta. Example difference plot used to examine the effects of simulated pit-digging on individual macrofaunal taxa. Values are differences between abundances in paired pits and controls

pits and controls in both variables up to $12 \mathrm{~d}$ and a consistent reduction in the difference between treatment and controls over time. After $24 \mathrm{~d}$ the number of taxa per core was very similar between controls and simulated pits but there was still a significantly lower number of individuals in pits.

Examination of the 16 most abundant taxa showed a similar pattern of reduced abundance in simulated pits for most taxa. Raw data plots (e.g. Fig. 6) showed that changes in difference between pits and controls could be described by a straight line in all cases. Plots for 12 species showed positive slopes with negative intercepts indicating a gradual equilibration between pits and controls with time, although the regression equations for these data were not significant because the slope was too shallow (Table 3). By $24 \mathrm{~d}$ the average abundance of most species in simulated pits was at, or very close to, control values. The only exceptions to this pattern were Urothoe elegans, which remained at a similar reduced mean abundance in simulated pits throughout the experiment, and the 2 most abundant taxa, Exogone hebes and Mediomastus sp., which showed increasing differences between pits and controls as the experiment progressed. This latter pattern resulted from an increase in control abundances with time while values in pits remained relatively constant. Nevertheless, despite the results for these 3 species, the overall picture of reduced abundance in pits is clear and is confirmed by Sign test which indicated that significantly more taxa occurred at high abundance in controls for all time periods sampled $(p<0.05)$.

Two species diversity measures show a strikingly consistent pattern in which samples taken from pits 

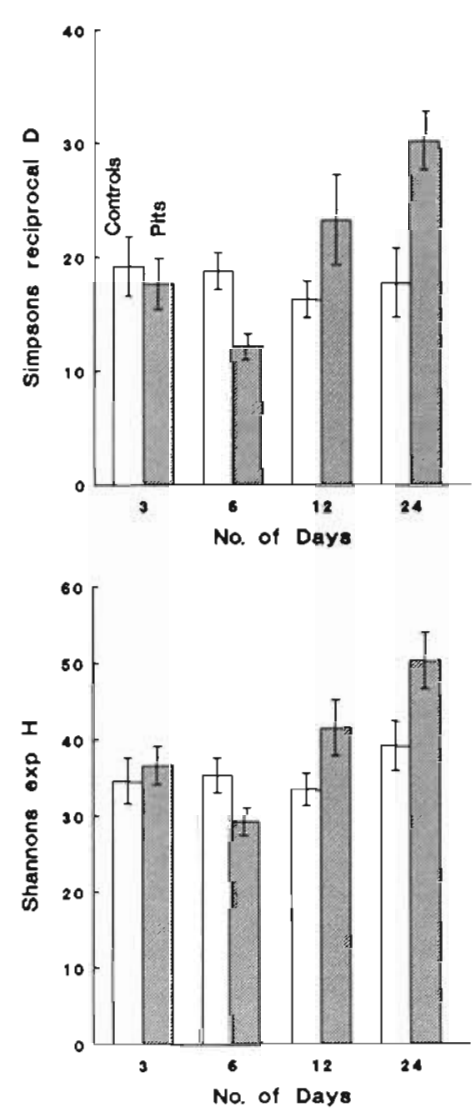

Fig. 7. Effects of simulated pit-digging on species diversity measures for the macrofaunal community. Hatched bars: pits; open bars: controls. Data are arithmetic means + 1 SEM

Fig. 8. Effects of simulated pit-digging on total number of larval individuals and taxa. Hatched bars: pits; open bars: controls. Data are arithmetic means + 1 SEM
Table 3. Regression equations describing the change in difference between abundance in simulated pits and controls for the 16 most abundant macrofaunal species in samples

\begin{tabular}{|lrrr|}
\hline Taxon & Intercept & Slope & $\mathrm{R}^{2}$ \\
\hline Exogone hebes & 0.435 & -0.319 & 0.060 \\
Mediomastus sp. & -2.087 & -0.501 & 0.238 \\
Oligochaetes & -1.830 & 0.065 & 0.004 \\
Sabellidae & -6.970 & 0.195 & 0.137 \\
Guernea coalita & -4.570 & 0.348 & 0.297 \\
Aricidea minuta & -3.860 & 0.157 & 0.094 \\
Tanaidae & -2.187 & 0.052 & 0.015 \\
Urothoe elegans & -3.604 & -0.097 & 0.017 \\
Prionospio cirrifera & -2.304 & 0.056 & 0.067 \\
Shaerosyllis sp. & -1.448 & 0.089 & 0.079 \\
Glycera lapidum & -0.891 & -0.012 & 0.003 \\
Harmothoe sp. & -1.617 & 0.084 & 0.056 \\
Aonides sp. & -2.161 & 0.070 & 0.092 \\
Kefersteinia cirrata & -1.000 & 0.120 & 0.189 \\
Lumbrineris gracilis & -0.370 & 0.022 & 0.008 \\
Ostracoda & -0.804 & 0.049 & 0.085 \\
& & & \\
\hline
\end{tabular}

had a lower diversity after $6 \mathrm{~d}$, but after 12 and $24 \mathrm{~d}$ diversity in pits was significantly greater than in controls (Fig. 7). This result can be accounted for by an increasing evenness in the distribution of species abundances, although examination of Whittaker plots of log relative abundance against species rank (Whittaker 1965) failed to reveal any marked differences between pits and controls.

Another potential effect of pit creation is the provision of patches for active colonisation, or passive inflow, by the larvae of infaunal taxa. During meiofauna analysis all juvenile stages of macrofauna (temporary meiofauna) were enumerated to test this hypothesis. The total numbers of individuals and taxa were consistently lower in simulated pits (Fig. 8), indicating that larvae were not preferentially settling in these areas.

To compare within- and between-treatment changes in sample similarity we calculated the Bray-Curtis statistic for all pair-wise comparisons between replicate pits (within-pit), replicate controls (within-control), and between replicate pit and control (between-treatment) samples. Fig. 9 shows the median values and 95\% confidence intervals for these data at each time point. As would be expected, within-control comparisons give the highest similarity values and these did not change significantly over the course of the experiment. Withinpit similarities were significantly lower than withincontrol values for all time points, although the data indicate that pits were becoming more similar to one another over time. The between-pit and control comparisons indicate that pits were also becoming more similar to controls with time, suggesting that the community was returning to its pre-disturbance state. 


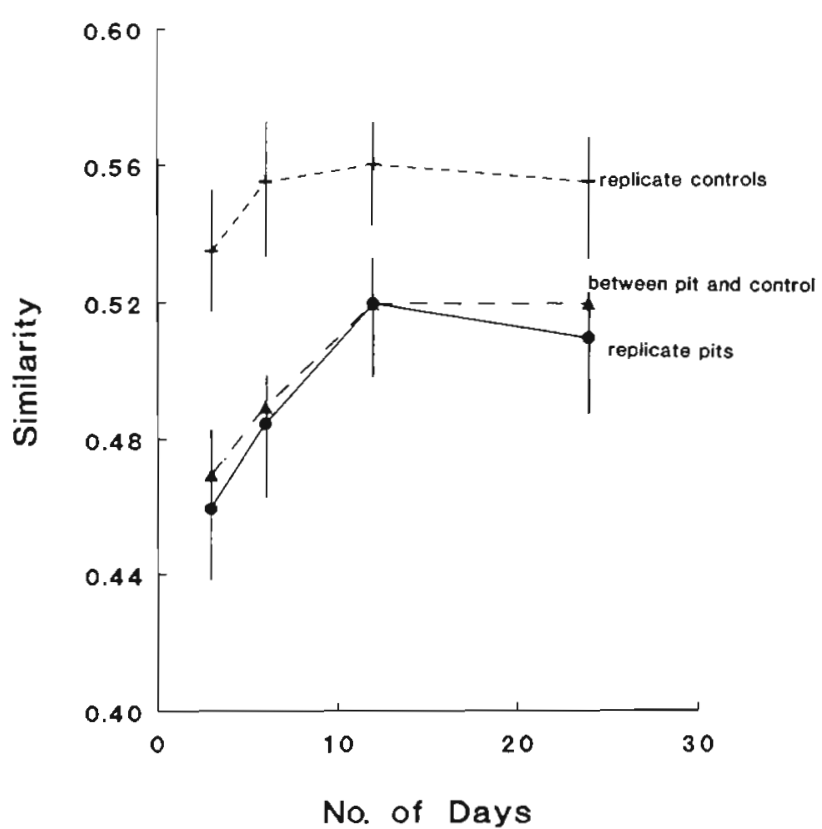

Fig. 9. Bray-Curtis similarity statistics for all pair-wise comparisons between replicate pits $(\bullet)$, replicate controls $(+)$ and between replicate pit and control samples (1)

One important question concerns the extent to which our pit simulations reflect the natural pit-digging process. To address this question we sampled 6 identifiable crab pits (each ca $5 \mathrm{~cm}$ deep) and immediately adjacent control sites. Although we do not know the age of these pits, Table 4 shows a pattern of reduced mean abundances of species and individuals that is consistent with our experimental results. Similarly, a Sign test revealed that a significant proportion of taxa were more abundant in undisturbed areas $(p<0.001)$. Examination of individual taxa, however, shows a somewhat contradictory pattern - the mean abundances of the 3 top ranked taxa (Exogene hebes, Oligochaetes and Mediomastus sp.) were higher in pits (Fig. 10). Closer examination of the raw data shows that this pattern is the result of unusually high abundances in 2 of the 6 pits. We have no additional data that can explain these 2 unusual pits but, in view of the fact that the pattern found for most pits was consistent with our experimental results, we are confident that our simulated pit-digging was representative of the disturbance caused by crabs.

Table 4. Abundance of individuals and species for natural crab pits and adjacent undisturbed areas

\begin{tabular}{|lrr|}
\hline & Pit & Control \\
\hline No. of individuals per core & $92.3+17.6$ & $117.3+12.6$ \\
No. of taxa per core & $22.7+1.9$ & $29.5+1.8$ \\
\hline
\end{tabular}

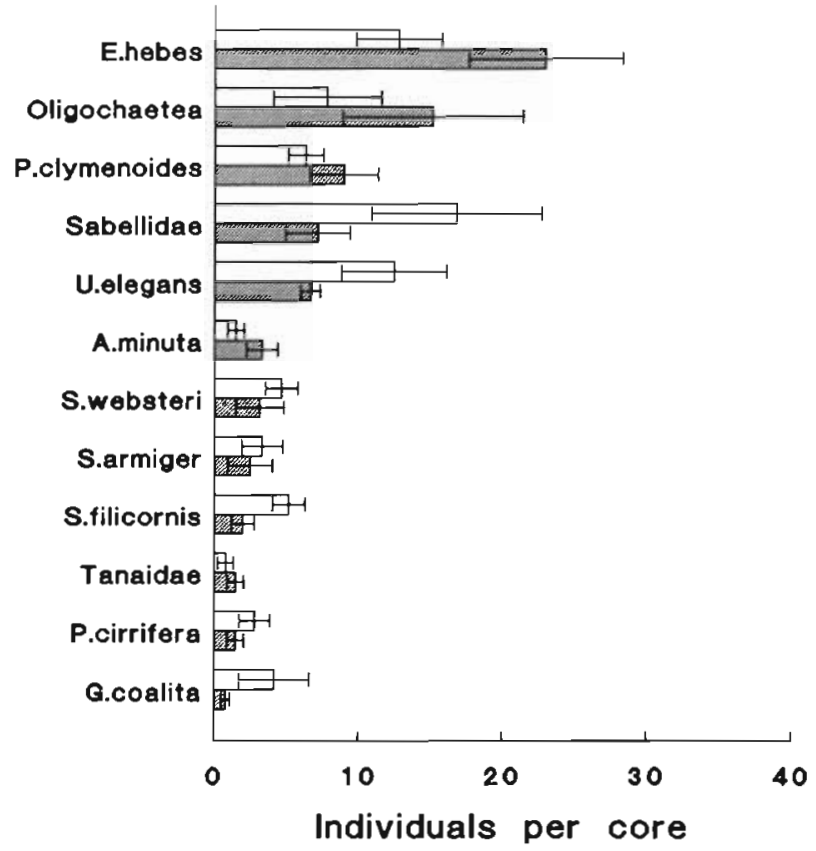

Fig. 10. Distribution of the 12 most abundant species in natural crab pits (hatched bars) and undisturbed areas (open bars). Data are arithmetic means + 1 SEM

\section{DISCUSSION}

Our results show that pit-digging on the same scale as that performed by crabs causes changes in sediment characteristics and reduction in the abundances of both meio and macrofauna. Effects on macrofauna were detectable after $24 \mathrm{~d}$, even though there were no surface signs of the pits.

Reductions in abundance are likely to be the result of 3 processes: displacement, predation and emigration. Displacement occurs because surface sediments and the animals they contain are pushed out of the pit; predation operates because mobile epifaunal predators (particularly fish and crabs) exploit the disturbed area and emigration may occur as individuals or species move out of the disturbed area. Following this initial reduction in animal numbers the relative importance of other processes will determine the dynamics of pits. These processes include detrital accumulation, larval recruitment, adult migration, and competitive and reproductive processes within the patch. It is within this phase that successional models are of interest.

We have found little evidence of disproportionate increases in the abundance of some taxa, that would be consistent with a competitive release (Grassle \& Sanders 1973) or food accumulation model in which organic matter accumulates in sediment depressions and is exploited by macrobenthic species which increase in abundance (Thistle 1980, 1981, Van Blaricom 1982). 
Rather, we observed a gradual return to the original community through the addition of displaced taxa and restoration of original densities. These results are consistent with those of Thrush (1986) who conducted a similar study on pit-digging by Cancer pagurus in a subtidal gravelly sediment and with the results of a number of other studies of disturbance (Sherman \& Coull 1980, Reidenauer \& Thistle 1981, Levin 1984, Nowell \& Jumars 1984, Savidge \& Taghon 1988). In all these cases it would appear that feeding or competitive interactions within disturbed patches were not altered enough to show as changes in the relative abundance of taxa.

Our analysis of within- and between-treatment similarity in the recolonisation experiment leads us to conclude that pit-digging had a variable effect on replicates in the disturbed treatment. If the same taxa were affected to the same extent in all disturbances we would expect the within-treatment similarities to be the same as controls. The result we obtained, however, implies that the identity of taxa affected by a disturbance and the magnitude of the effect is unpredictable.

The mechanisms by which disturbed patches are recolonised remains unresolved but because pits were filled in within 3 to $6 \mathrm{~d}$ the initial phase of recovery is likely to be through erosion from the surrounding sediments. However, Van Blaricom (1982) reported shortterm peaks in abundance of some species over this time scale and species of the same genus (Megalorupus sp. and Monoculodes sp.) are present at our study site. The simplest interpretation for the period from Day 3 onward is that species colonised at random from the available pool, either through transport in the water column or by migration through the sediments.

We have not included in this discussion short-term responses by epibenthic predators, such as fish, crabs or shrimps, which actively feed in disturbed sediment during and immediately after pit-digging (Nerini \& Oliver 1983, Oliver et al. 1983, 1985). On this time scale a model of patch dynamics based on feeding responses is appropriate. Predation by mobile epibenthic predators will be dealt with elsewhere.

We have estimated that in any given $1000 \mathrm{~m}^{2}$ area there will be 20 pits dug each day. Of these a minimum of 3 are likely to be feeding pits, although we may expect a greater number of large pits if crabs are unsuccessful in some feeding attempts. (Judging from the number of pits dug at night and the frequency with which we observed chains of pits in a localised area, such unsuccessful feeding attempts seem likely.) The modal sizes for feeding and resting pits are 0.25 and $0.04 \mathrm{~m}^{2}$, respectively. Thus, we estimate that ca $0.0015 \%$ of the habitat are disturbed each day. We show that disturbances were clearly detectable after 24 $\mathrm{d}$ but, unfortunately, we have no observations beyond this so that $24 \mathrm{~d}$ represent a minimum life for a dis- turbed patch. Using this minimum we estimate that ca $3.6 \%$ of the area will be at some stage of recovery from disturbance by pit-digging. This value rises to ca $6 \%$ if we extend pit life to $30 \mathrm{~d}$, which is reasonable judging from the trajectories for total numbers of macrofauna individuals in pit and control areas. On this basis it would seem that, although the foraging activities of Cancer have profound effects on a local scale they are unlikely to be important on a larger scale for maintaining communities at any kind of competitive disequilibrium. 'Back of the envelope' calculations of this kind are, of course, somewhat speculative, but we feel that this estimate is a reasonable one based on the available data. To be more certain, however, experiments which manipulate the density of $C$. pagurus over long time scales are required.

Acknowledgements. We thank D. Baird and D. Bova for help with diving, and M. Wilson and S. Miller for help with sample sorting.

\section{LITERATURE CITED}

Basford, D., Eleftheriou, A. (1988). The benthic environment of the North Sea. J. mar biol. Ass. UK. 68: 125-141

Connell, J. H. (1978). Diversity in tropical rain-forests and coral reefs. Science 199: 1302-1310

Grassle, J. F., Sanders, H.L. (1973). Life histories and the role of disturbance. Deep Sea Res. 20: 643-659

Hall, S. J., Raffaelli, D., Basford, D. J., Robertson, M. R. (1990a). The importance of flatfish predation and disturbance on marine benthos: an experiment with dab (Limanda limanda). J. exp. mar. Biol. Ecol. 136: 65-76

Hall, S. J., Raffaelli, D., Robertson, M. R., Basford, D. J. (1990b). The role of the predatory crab, Liocarcinus depurator, in a marine food web. J. Anim. Ecol. 59: $421-438$

Hawkins, A. D., Urquhart, G. G., Smith, G. W. (1980). Ultrasonic tracking of juvenile cod by means of a large spaced hydrophone array. In: Amlaner, C. J., MacDonald, D. W. (eds.) A handbook on biotelemetry and radio tracking. Pergamon, Oxford, p. 461-470

Holme, N. A., McIntyre, A. D. (1984). Methods of the study of marine benthos. Blackwell Scientific Publications, Oxford

Johnson, R. G. (1970). Variations in diversity within benthic marine communities. Am. Nat. 104: 285-300

Johnson, R. G. (1973). Conceptual models of benthic communities. In: Schopf, T. J. M. (ed. ) Models in paleobiology. Freeman Cooper \& Co, San Francisco, p. 148-159

Krebs, C. J. (1989). Ecological methodology. Harper and Row, New York

Levin, L. A. (1984). Life history and dispersal patterns in a dense infaunal polychaete assemblage: community structure and response to disturbance. Ecology 65: 1185-1200

Nerini, M. K., Oliver, J. S. (1983). Gray whales and the structure of the Bering Sea benthos. Oecologia (Berl.) 59: 224-225

Nowell, A. R. M., Jumars, P. A. (1984). Flow environments of aquatic benthos. Ann. Rev. Ecol. Syst. 15: 303-328

Oliver, J. S., Slattery, P. N. (1985). Destruction and opportunity on the sea floor: effects of gray whale feeding. Ecology 66 : 1965-1975 
Oliver, J. S., Slattery, P. N., O'Connor, E. F., Lowry, L. F (1983). Walrus, Odobenus rosmarus, feeding in the Bering Sea: a benthic perspective. Fish. Bull. U.S. 81: 501-512

Oliver, J. S., Kvitek, R. G., Slattery, P. N. (1985). Walrus feeding disturbance: scavenging habits and recolonisation of the Bering Sea benthos. J. exp. mar. Biol. Ecol. 91, 233-246

Peet, R. K. (1974). The measurement of species diversity. Ann. Rev. Ecol. Syst. 5: 285-307

Reidenauer, J. A., Thistle, D. (1981). Response of a soft-bottom harpactacoid community to stingray (Dasyatis sabina) disturbance. Mar. Biol. 65: 261-267

Savidge, W. B., Taghon, G. L. (1988). Passive and active components of colonisation following two types of disturbance on intertidal sandflat. $J$. exp. mar. Biol. Ecol. 115: $137-155$

Shelton, R. G. G., Kinnear, J, Livingston, K. (1979). A preliminary account of the feeding habits of the edible crab (Cancer pagurus) off north west Scotland. Int. Counc. Explor. Sea Comm. Meet. ICES CM K: 1-35

Sherman, K. M., Coull, B. C. (1980). The response of meiofauna to sediment disturbance. J. exp. mar. Biol. Ecol. 46: $59-71$

This article was submitted to the editor
Siegle, S. (1956). Non-parametric statistics for the behavioural sciences. McGraw-Hill, Tokyo

Strickland, J. D. H., Parsons, T. R. (1972). A practical handbook of seawater analysis. Bull. Fish. Res. Bd Can. 167

Thistle, D. (1980). The response of a harpactacoid copepod community to a small-scale natural disturbance. J. mar. Res. 38: 381-395

Thistle, D. (1981). Natural physical disturbances and communities of marine soft bottoms. Mar. Ecol. Prog. Ser. 6: 223-228

Thrush, S. F. (1986). Spatial heterogeneity in subtidal gravel generated by the pit-digging activities of Cancer pagurus. Mar. Ecol. Prog. Ser. 30: 221-227

Uhlig, G., Thiel, H., Gray, J. S. (1973). The quantitative separation of meiofauna. Helgolander wiss. Meeresunters. 25: 173-195

Van Blaricom, G. R. (1982). Experimental analysis of structural regulation in a marine sand community exposed to oceanic swell. Ecol. Monogr. 52: 283-285

Whittaker, R. H. (1965). Dominance and diversity in land plant communities. Science 147: 250-260.

Manuscript first received: November 28, 1990

Revised version accepted: March 4, 1991 